\title{
MAPEAMENTO GEOTÉCNICO REGIONAL NA ESCALA 1:100.000 - CONSIDERAÇÕES METODOLÓGICAS
}

\author{
Osni José PEJON \\ Lázaro Valentin ZUQUETTE
}

\begin{abstract}
RESUMO
Apresentam-se neste trabalho algumas considerações metodológicas quanto à definição e forma de obtenção dos atributos em mapeamentos geotécnicos regionais, principalmente na escala 1:100.000. Observa-se que, para mapeamentos nesta escala, os atributos fundamentais devem ser obtidos por matrizes que permitam analisar o inter-relacionamento entre os atributos. Com esta análise, verificou-se que os atributos naturais relacionados ao campo de conhecimento da Geologia são os que apresentam relação com a maior parte dos demais atributos mapeados. São ainda analisadas neste artigo as formas de apresentação gráfica dos resultados, concluindo-se que as cartas de zoneamento geotécnico geral e específico são mecanismos muito eficientes para representar as informações e interpretações obtidas no mapeamento geotécnico.
\end{abstract}

\section{ABSTRACT}

Methodological considerations are presented on the choice, obtention and graphic representation of attributes in engineering geological mapping, especially at the 1:100.000 scale. In this scale the selection of attributes should be done by matrices permitting the analysis of relationships among attributes. Such an analysis showed that there are strong relations among the geologic attributes and other kinds considered. Specific and general engineering geological zoning maps are efficient mechanisms for graphic representations of the attributes and for interpretation.

\section{INTRODUÇÃO}

O mapeamento geotécnico em escala regional é um importante instrumento de obtenção e apresentação das informações do meio físico visando principalmente ao uso racional do terreno e ao planejamento ambiental. Desta forma, as questões metodológicas de elaboração desses mapas revestem-se de grande importância.

Neste trabalho discutem-se alguns aspectos metodológicos dos mapeamentos geotécnicos regionais e principalmente sobre aqueles realizados na escala 1:100.000, por considerarse que os mapas executados nesta escala são adequados aos estudos do meio físico visando ao planejamento regional. Apresenta-se neste trabalho uma metodologia para definição dos atributos que devem ser utilizados no mapeamento e também no modo de organizar as informações em mapas e cartas, básicas e interpretativas.

\section{IMPORTÂNCIA DO MAPEAMENTO GEOTÉCNICO REGIONAL NA ESCALA 1:100.000}

Analisando-se algumas metodologias já consagradas e conhecidas mundialmente, notase que os trabalhos de mapeamento geotécnico na escala 1:100.000 representam quase sempre uma transição entre escalas grandes e pequenas. Segundo a metodologia da escola francesa, sintetizada por SANEJOUAND (1972), os trabalhos na escala 1:100.000 destinam-se ao planejamento de áreas metropolitanas, enquanto a metodologia da IAEG-UNESCO (1976) classifica os documentos nesta escala como destinados ao planejamento regional. A metodologia australiana (GRANT, 1970) considera a escala 1:100.000 como limite para utilização das classes de padrão de terreno. Na Espanha, os mapas geotécnicos nesta escala são elaborados conjuntamente com os mapas geotécnicos gerais (escala 1:200.000), para analisar e mostrar alguns dos aspectos relevantes do meio ou 
situações de risco a nível regional, como por exemplo a erosão ou a estabilidade de taludes (FARIAS et al., 1984).

No Brasil, em proposta metodológica de mapeamento geotécnico para as condições brasileiras, ZUQUETTE (1987) também coloca os mapas em escala 1:100.000 como documentos com finalidades regionais, representando a transição para os mapas gerais.

Outra constatação feita com a análise dos diversos trabalhos consultados é que os mapas e cartas produzidos na escala 1:100.000 são importantes, muito utilizados e confeccionados na maioria dos países que usam os processos de mapeamento geotécnico para a caracterização do meio físico. Mas, pelo fato de a escala em que são elaborados representar uma transição, onde se tem a alteração do nível de informações, dos atributos a analisar e das finalidades a que se destinam os documentos, ocorre uma grande dificuldade na definição das informações que devem constar nessas cartas ou mapas, como devem ser obtidas e apresentadas.

Considerando a metodologia de ZUQUETTE (1987), fica patente este tipo de situação, uma vez que o autor classifica como regionais os documentos gráficos produzidos em escalas entre 1:25.000 e 1:100.000. Logo, o nível de informações, os atributos analisados e a forma de apresentação, por exemplo, não devem ser iguais para as cartas e mapas em uma e noutra escala. Este fato ocorre com a maioria das metodologias analisadas. Assim, busca-se neste trabalho definir os atributos fundamentais, como obtê-los e como apresentar as informações em mapeamentos na escala 1:100.000.

\section{DEFINIÇÃO DOS ATRIBUTOS}

A definição dos atributos a serem utilizados está relacionada à finalidade e à escala do trabalho. Da escolha dos atributos corretos depende em grande parte a eficiência e a qualidade do mapeamento. ZUQUETTE (1987) afirma que o problema crucial na realização dos trabalhos de mapeamento geotécnico consiste em definir, isolar e identificar os atributos necessários para o correto estabelecimento das unidades componentes dos documentos.

ZUQUETTE (1991) estabeleceu, dentro de alguns campos do conhecimento, os atributos associados ao planejamento (Tab. 1). Dentre estes, selecionaram-se aqueles considerados importantes dentro dos estudos do meio físico realizados nos mapeamentos geotécnicos, como indicado na tabela 1 (números de 1 a 49).

Quando se trata de um trabalho em escala regional, para uso geral, a definição dos atributos a serem mapeados deve considerar o seu inter-relacionamento com os demais atributos. Para esta análise, o método das matrizes (VARNES, 1974) pode ser muito útil. Assim, montou-se uma matriz atributo versus atributo (Fig. 1), com os 49 atributos selecionados na tabela 1 .

Analisando-se esta matriz, verifica-se que, dentre os 49 atributos, tem-se 14 que apresentam relação com mais de $50 \%$ dos demais. Depreende-se desta análise a importância da consideração desses atributos quando da realização do mapeamento geotécnico. Assim sendo, percebe-se que os atributos tipo litológico e tipo rochoso são os que apresentam maior relacionamento com os demais, seguidos pela textura e origem dos materiais inconsolidados, todos pertencentes ao campo do conhecimento da geologia. No campo da geomorfologia, os landforms são os mais importantes, enquanto que, no campo de conhecimento das águas, tem-se os atributos escoamento superficial e infiltração como de grande relevância.

Portanto, em um mapeamento geotécnico em escala regional, esses atributos necessariamente devem ser levantados e analisados, pois o seu estudo pode propiciar conhecimentos mais adequados sobre os componentes do meio físico.

Nos mapeamentos geotécnicos com finalidades específicas podem ser montadas outras matrizes, do tipo atributo versus tipo de ocupação, para definição dos atributos fundamentais a serem analisados.

\section{OBTENÇÃO DAS INFORMAÇÕES}

Segundo SEARLES, 1956 (apud VARNES, 1974), uma classificação deve basear-se tanto nas propriedades naturais dos materiais, quanto nos propósitos ou finalidades a que se destina. Em mapeamentos geotécnicos na escala 1:100.000, deve-se priorizar a obtenção de informações sobre propriedades e atributos dos materiais que reflitam sua natureza, permitindo assim sua classificação.

Os atributos fundamentais, relacionados no item anterior, devem ser considerados em todos os trabalhos de mapeamento geotécnico, qualquer que seja a escala, devido a sua importância na identificação das unidades naturais e por sua relação com os demais atributos. Desta maneira, um mapa geotécnico com finalidades regionais teria uma divisão em unidades naturais, baseadas nos atributos fundamentais. As cartas de finalidades específicas apresentariam também os atributos fundamentais, acrescidos da análise de atributos específicos, podendo 
TABELA 1 - Informações fundamentais para o planejamento (apud ZUQUETTE, 1991)

\begin{tabular}{|c|c|c|c|}
\hline $\begin{array}{l}\text { Campos de } \\
\text { conhecimento }\end{array}$ & Tipo/Aspecto & Grupos de Atributos & Atributos \\
\hline Águas & $\begin{array}{l}\text { superficiais } \\
\text { subterrâneas }\end{array}$ & & $\begin{array}{l}\text { *1 - escoamento } \\
\text { *2 - infiltração } \\
3 \text { - áreas de acúmulo de águas } \\
4 \text { - características físico- } \\
\text { químicas livres } \\
5 \text { - aquiúferos \{confinados } \\
6 \text { - áreas de recarga } \\
7 \text { - profundidade/espessuras } \\
\text { - poços } \\
\text { - senilidade } \\
8 \text { - características físico- } \\
\text { químicas }\end{array}$ \\
\hline \multirow[t]{2}{*}{ Geomorfologia } & morfometria & & $\begin{array}{l}9 \text { - altitudes } \\
10 \text { - declividade e sentido }\end{array}$ \\
\hline & morfografia & unidades básicas & $\begin{array}{l}* 11 \text { - landforms }\left\{\begin{array}{c}\text { encosta bacia } \\
\text { de inundação }\end{array}\right. \\
* 12 \text { - formas de encostas } \\
* 13 \text { - comprimentos das encostas } \\
\text { ou landforms }\end{array}$ \\
\hline \multirow[t]{4}{*}{ Geologia } & \multirow[t]{2}{*}{ substrato rochoso } & materiais & $\begin{array}{l}\text { *14 - tipo rochoso } \\
\text { *15 - litologia } \\
16 \text { - mineralogia } \\
17 \text { - densidade } \\
18 \text { - resistência } \\
19 \text { - permeabilidade } \\
20 \text { - estruturas } \\
21 \text { - distribuição } \\
22 \text { - profundidade } \\
\text { *23 - grau de intemperismo } \\
\text { *24 - alterabilidade } \\
25 \text { - potencial para material de } \\
\text { construção }\end{array}$ \\
\hline & & processos & $\begin{array}{l}26 \text { - erosão } \\
27 \text { - deposição } \\
28 \text { - sismicidade } \\
29 \text { - subsidência }\end{array}$ \\
\hline & \multirow[t]{2}{*}{$\begin{array}{l}\text { materiais } \\
\text { inconsolidados }\end{array}$} & gerais & $\begin{array}{l}* 30 \text { - origem, textura, } \\
* 31 \text { - distribuição } \\
32 \text { - permeabilidade } \\
33 \text { - índice de vazios } \\
34 \text { - mineralogia } \\
35 \text { - erodibilidade } \\
36 \text { - fertilidade } \\
37 \text { - potencial de corrosividade }\end{array}$ \\
\hline & & específicos & $\begin{array}{l}38 \text { - expansibilidade } \\
\text { *39 - variação em profundidade } \\
40 \text { - características químicas } \\
\text { (pH,...) } \\
41 \text { - capacidade campo e mur- } \\
\text { chamento } \\
\text { *42 - processos de intemperis- } \\
\text { mo e pedológicos } \\
43 \text { - resistência/suporte } \\
44 \text { - massas específicas dos } \\
\text { sólidos e aparente seca } \\
45 \text { - potencial para aterros (cont.) }\end{array}$ \\
\hline
\end{tabular}




\begin{tabular}{|c|c|c|c|}
\hline \multirow[t]{3}{*}{ Biológicos } & $\begin{array}{l}\text { cadeia alimentar } \\
\text { habitat } \\
\text { animais }\end{array}$ & $\begin{array}{l}\text { aquáticos } \\
\text { terrestres }\end{array}$ & $\begin{array}{l}\text { - interdependência entre } \\
\text { vários organismos } \\
\text { - salinidade, temperatura, } \\
\text { profundidade } \\
\text { - tipo, B.O.D., C.O.D. } \\
\text { - Sedimentos } \\
\text { - tipos }\end{array}$ \\
\hline & & & $\begin{array}{l}\text { - inventário } \\
\text { - anomalias }\end{array}$ \\
\hline & vegetação & tipo & $\begin{array}{l}\text { - distribuição e tendências } \\
\text { - valor econômico ou pre- } \\
\text { servacionista }\end{array}$ \\
\hline Clima & & & $\begin{array}{l}\text { *46 - pluviosidade } \\
47 \text { - temperatura } \\
\text { - umidade relativa } \\
\text { - ventos } \\
\text { - insolação } \\
48 \text { - evapotranspiração } \\
49 \text { - intensidades pluviométricas }\end{array}$ \\
\hline Culturais & $\begin{array}{l}\text { sociais } \\
\text { educacionais } \\
\text { econômicos }\end{array}$ & & $\begin{array}{l}\text { - população, saúde } \\
\text { - escolas } \\
\text { - uso do solo, indústrias }\end{array}$ \\
\hline
\end{tabular}

$1,2,3, \ldots$ - Atributos que devem ser objeto de estudo dos mapeamentos geotécnicos.

* Atributos que apresentam relação com mais que $50 \%$ dos demais.

resultar tanto na subdivisão quanto no agrupamento das unidades em função do propósito da carta e da complexidade da região. No caso de mapeamentos geotécnicos na escala 1:100.000, torna-se mais evidente a necessidade de caracterização das unidades por meio de atributos que reflitam a natureza dos materiais envolvidos, tais como: gênese, textura, composição mineralógica, litologia, formas de terreno (landforms ), etc. Na obtenção dessas informações deve-se buscar a utilização de métodos alternativos, sempre que os tradicionais resultarem em tempo muito longo e/ou custo elevado.

\section{APRESENTAÇÃO DAS INFORMAÇÕES}

A apresentação das informações é um dos pontos do mapeamento geotécnico de maior importância, pois é por intermédio dos documentos gráficos e memoriais descritivos que se faz a comunicação dos técnicos que elaboraram o trabalho com os usuários finais. De uma adequada apresentação dos resultados podem depender a aceitação e aproveitamento das informações fornecidas.

A mancira de apresentação, embora considerada um estádio final do processo de mapeamento, está diretamente relacionada com o procedimento que se deve adotar no transcorrer do trabalho. Portanto, deve ser definida, desde o início dos estudos, a seqüência (fluxograma) de obtenção e manipulação das informações, bem como os documentos que serão produzidos em cada etapa.

Considerando-se a proposta metodológica de ZUQUETTE (1987) e a de MATULA (1979), propõe-se uma orientação seqüencial de obtenção e apresentação das informações para mapeamentos geotécnicos em escala regional, como mostrado na figura 2 .

Os componentes e processos do meio físico devem ser analisados em função de seus atributos naturais e fundamentais, os quais foram definidos no item 3 , em função de sua importância e inter-relacionamento.

A etapa de elaboração dos mapas das condições geológico-geotécnicas consiste em uma fase analítica, onde o produto gráfico é uma série de mapas básicos representando as características naturais do meio físico. Estes documentos podem ser correlacionados às cartas de fatores da metodologia francesa (SANEJOUAND, 1972), ou aos mapas analíticos da classificação da IAEG-UNESCO (1976), ou seja, documentos gráficos como: mapa do substrato rochoso, de materiais inconsolidados, de landforms, de processos geodinâmicos e carta de declividade, representando, portanto, componentes individuais do meio físico, sua variação e distribuição. 
$\mathrm{Na}$ etapa seguinte, por meio da análise da distribuição espacial e inter-relação entre os componentes, são obtidas as cartas de zoneamento geotécnico geral e específico. Segundo MATULA (1979), uma unidade de zoneamento consiste em um modelo espacial tridimensional, baseado em uma certa homogeneidade das condições geotécnicas. GWINNER, 1956 (apud PETER, 1966) já utilizava o conceito de zona como uma unidade geotécnica de comportamento homogêneo, independente da variação litológica, de solos ou estruturas.

Desta maneira, o zoneamento geotécnico compreende a divisão de uma determinada área em função da avaliação de inter-relações e covariações entre os componentes do meio físico. Assim, quando se associa um mapa com informações sobre o tipo de material inconsolidado, com a declividade e a profund̦idade do substrato rochoso, está se procedendo à individualização da região em zonas com característi- cas próprias, advindas dos componentes que foram combinados.

A escolha dos atributos utilizados no zoneamento depende dos objetivos e finalidades desejadas ou previstas. As cartas de zoneamento geotécnico podem ser divididas em dois grandes grupos: geral e específico (ZUQUETTE, 1987). As primeiras caracterizam-se por apresentarem uma combinação de atributos independentes da sua possível utilização. Devem distinguir zonas homogêneas em relação às condições naturais, sem se prender à solução de um problema específico.

As cartas de zoneamento geotécnico específico são obtidas por meio da combinação de atributos visando a um uso específico, como, por exemplo, a obtenção de material para construção, produção de cartas de risco, de irrigação, para disposição de rejeitos, entre outras. Segundo o esquema proposto na figura 2, podese ainda elaborar um último conjunto de cartas,

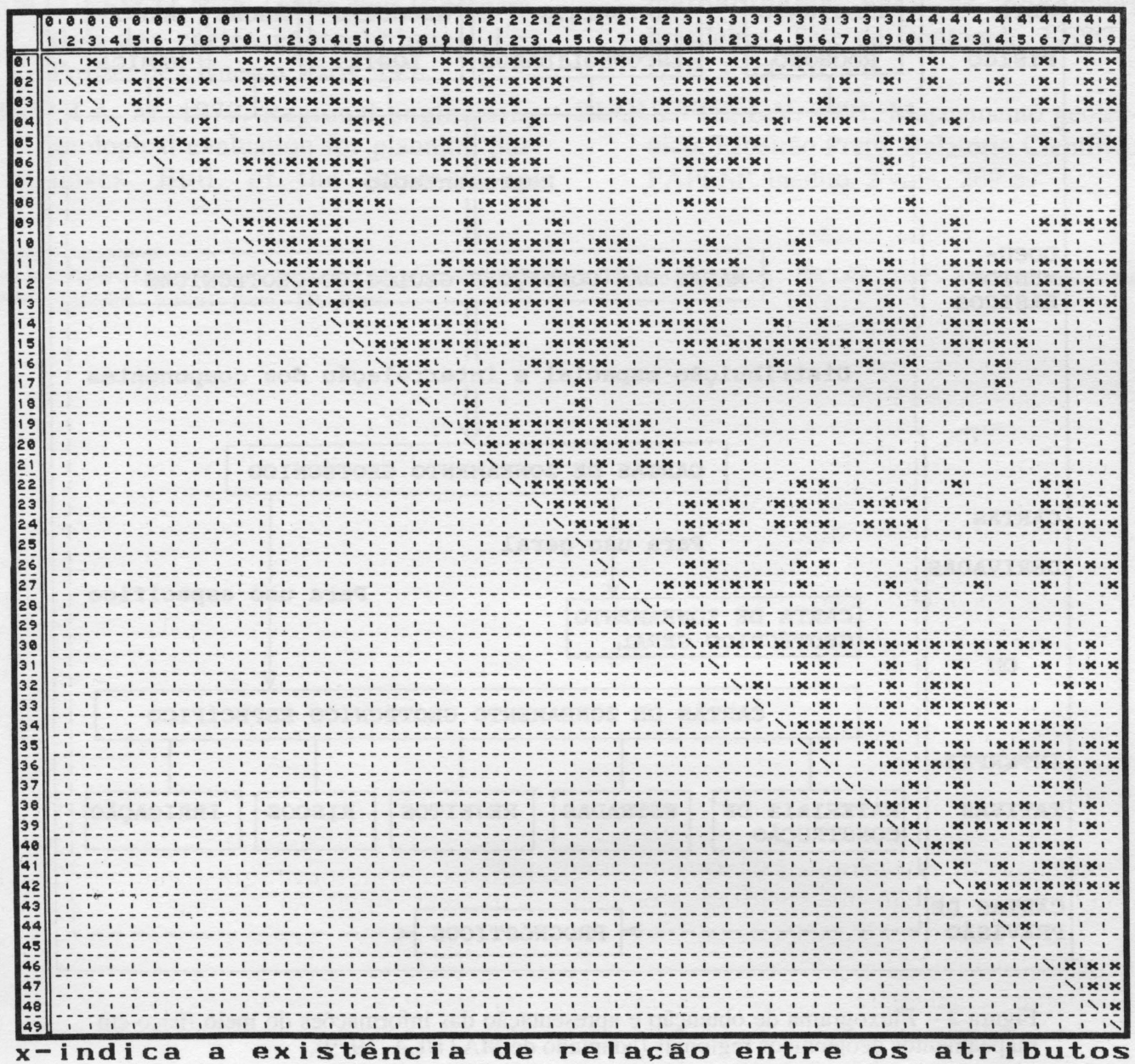

FIGURA 1 - Matriz atributo x atributo. 
chamadas de cartas de previsão ou prognósticos, nas quais podem ser analisadas as respostas do meio físico frente às modificações processadas, tanto a nível dos componentes individuais do meio físico, quanto às unidades de zoneamento. Estas cartas podem ser muito úteis quando se pretende usar o mapeamento geotécnico no planejamento, pois permitem considerar as prováveis mudanças provocadas pelos diversos tipos de ocupação. Para a sua elaboração deve-se contar com uma equipe multidisciplinar, de maneira a permitir uma correta avaliação das possíveis formas de ocupação.

\section{CONSIDERAÇÕES FINAIS}

Os trabalhos de mapeamento geotécnico regional devem estar baseados em atributos fundamentais do meio físico, que por sua vez são selecionados devido à sua inter-relação com os demais atributos e em função da finalidade a que se destina o trabalho. Para identificação destes atributos o método das matrizes é o mais adequado.

A determinação das características geotécnicas das unidades deve ser feita por meio de ensaios simples e de baixo custo. A forma de apresentação dos resultados é importante e sua definição é necessária desde os estádios iniciais do trabalho. Segundo os estudos realizados, as cartas de zoneamento geotécnico geral e específico são as formas mais eficientes de representação das informações obtidas.

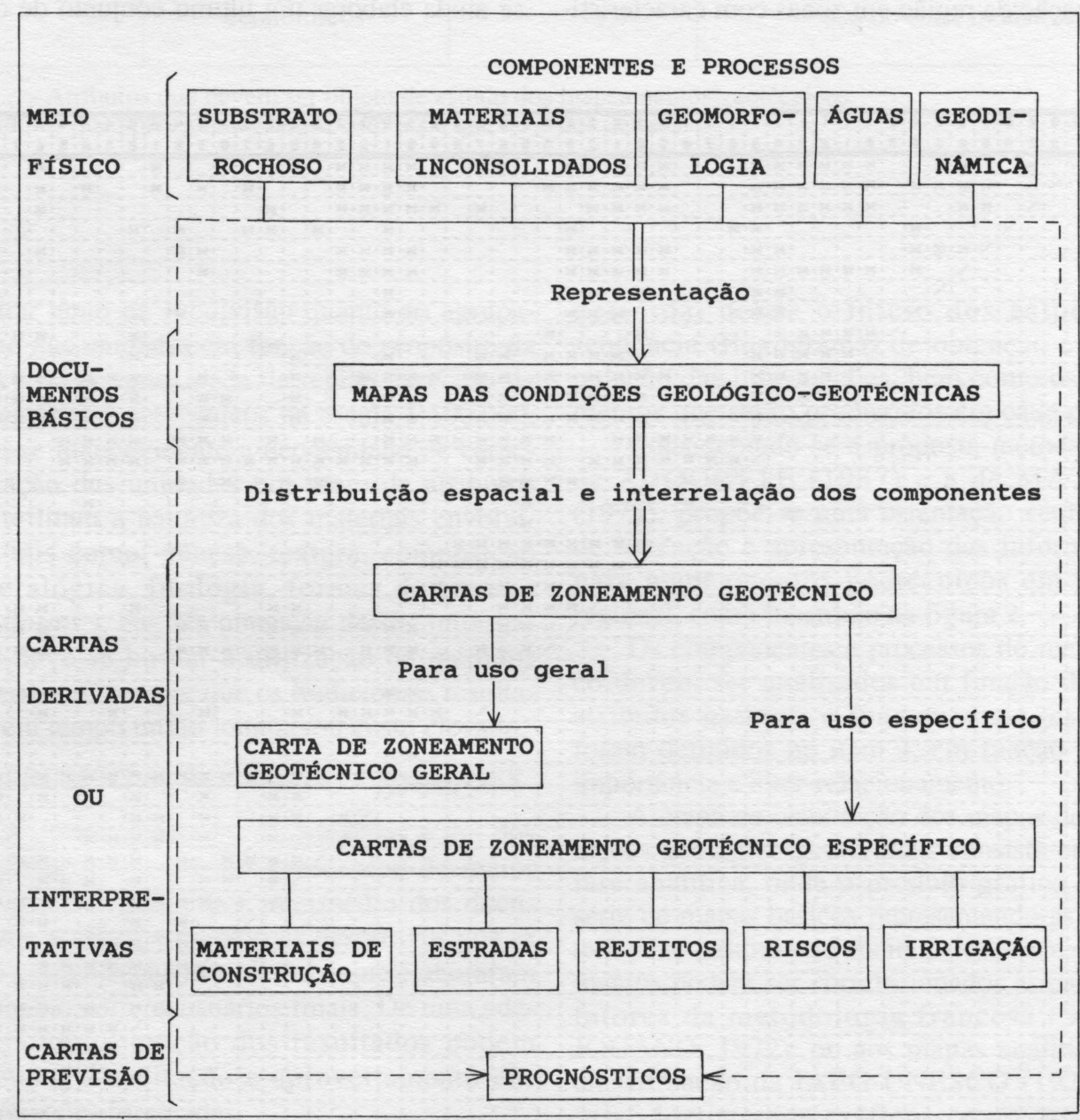

Figura 2 - Fluxograma de obtenção e apresentação das informações do meio físico em mapeamentos geotécnicos regionais (adaptado de MATULA, 1979). 


\section{REFERÊNCIAS BIBLIOGRÁFICAS}

FARIAS, I.C.; ALONSO, M.A.; MAQUA, M.P.A.; CANALS, E.A.; ANDRAY, A.B.; PRIETO-LAVIN, T.C.; GONZÁLEZ-FIERRO, M.A.C.; VEGA, P.C.; BOMB-N, R.E.; ARRIOLA, E.F.; CALCERÁN, G.C.; ALONSO, S.G.; MENDIZ, E.L.; RODRIGUEZ, C.M.; HERNÁNDEZ-ACERO, C.O.; PASTOR, I.O.; FERNÁNDEZ, A.R.; OMEÑACA, M.G.S. 1984. Guia para la elaboracion de estudios del medio físico; contenido y metodologia. Centro de Estudios de Ordenacion del Territorio y Medio Ambiente, Espanha, 572 p.

GRANT, K. 1970. Terrain Evaluation. A logical extension of engineering geology. In: Proceedings of the $1 \mathrm{st}$ I.A.E.G. Congress. Paris, 2: 971-980.

GWINNER, G. 1956. Carte géotechnique de la ville de Göttingen, Berlin.

IAEG-UNESCO 1976. Guide pour la préparation des cartes géotechniques. Les Presses de l'Unesco. Paris. 79 p.

MATULA, M. 1979. Regional engineering geological evaluation for planning purposes. Bull. of the International
Association of Engineering Geology. Krefeld, (19): 18-24.

PETER, A. 1966. Éssai de carte géotechnique. Soils Soils, (16): 13-27.

SANEJOUAND, R. 1972. La cartographie géotechnique en France. Paris, Ministère de l'Equipement et du Logement. D.A.F.U.; A.R.M.I.N.E.S., L.C.P.C., 95p.

SEARLES, H.L. 1956. Logic and scientific methods ( $2^{\text {nd }}$ ed) New York, Ronald Press, 378p.

VARNES, D.J. 1974. The logic of geological maps, with reference to their interpretation and use for engineering purposes. U.S.A., Geological Survey - profissional paper $837,48 \mathrm{p}$.

ZUQUETTE, L.V. 1987. Análise crítica da cartografia geotécnica e proposta metodológica para as condições brasileiras. Tese de Doutorado. EESC USP. 3 vols., 673 p.

ZUQUETTE, L.V. 1991. Mapeamento geotécnico: Ribeirão Preto. Relatório Científico FAPESP, inédito. 2 vols., 269 p.

Endereço dos autores:

Osni José Pejon e Lázaro Valentin Zuquette - Departamento de Geologia, Física e Matemática - FFCLRP - USP - Avenida Bandeirantes, 3.900 - 14040-901 - Ribeirão Preto - SP - Brasil. 